\title{
HISTORIA Y FUNDAMENTOS DE LA EXTENSIÓN DE EFECTOS DE SENTENCIAS FIRMES COMO FIGURA PROCESAL AUTÓNOMA
}

\author{
History and foundations of the extension of effects of final \\ judicial sentences as autonomous procedural figure
}

\author{
María Luisa Domínguez Barragán \\ Profesora de Derecho Procesal \\ Universidad de Córdoba \\ mldominguez@uco.es
}

http://dx.doi.org/10.18543/ed-67(2)-2019pp235-261

Recibido: 23.07.2019

Aceptado: 16.12.2019

\section{Resumen}

En este trabajo se abordan los aspectos históricos de la introducción de la extensión de efectos de sentencias firmes en el ordenamiento jurídico nacional y el impacto que esta figura ha tenido en el ámbito contencioso-administrativo desde una perspectiva procesal. Igualmente, se exponen sus fundamentos tanto sustantivos como formales, acercando esta herramienta (que es bastante desconocida) a los operadores jurídicos. Cuestiones como el derecho a la tutela judicial efectiva, la ejecución de sentencias o la extensión de la cosa juzgada son sometidas a revisión cuando entra en juego un instrumento de estas características. Pero, ¿realmente es tanta su eficacia como para justificar su difícil encaje en el ordenamiento? De ahí radica la importancia de conocer su historia y de establecer su fundamentación.

\section{Palabras clave}

Extensión de efectos, sentencias firmes, derecho a la tutela judicial efectiva, ejecución, cosa juzgada. 


\section{Abstract}

This paper addresses the historical aspects of the introduction of the extension of effects of final judgments in the national legal order and the impact this figure has had on the contentious-administrative field from a procedural perspective. Likewise, both substantive and formal foundations are expounded, bringing this tool closer, (which is quite unknown) to legal operators. Issues such as the right to effective judicial protection, the execution of judgments or the extension of res judicata are subject to review when such an instrument comes into play. But, Is it really so effective as to justify its difficult fit into the legal system? Hence the importance of knowing its history and establishing its foundations.

\section{Keywords}

Extension of effects, final judgments, effective judicial protection, execution, res judicata. 


\begin{abstract}
SUMARIO: I. INTRODUCCIÓN. II. ANTECEDENTES HISTÓRICOS. III. FuNDAMENTOS DE LA FIGURA. 1. Clasificación de los fundamentos. 1.1. Razones que cimentan la extensión de efectos en el ámbito general. 1.2 Razones que fundamentan la extensión para la esfera del ciudadano. 1.3. Razones de carácter técnico. 2. Visión jurisprudencial. IV. A MODO DE CONCLUSIÓN: OBJETIVOS DE LA FIGURA. BIBLIOGRAFÍA.
\end{abstract}

\title{
I. INTRODUCCIÓN
}

Hablar de extensión de efectos de sentencias firmes en el ordenamiento jurídico nacional pasa necesariamente por el ámbito contencioso-administrativo. Nos encontramos ante una figura procesal desconocida, de carácter novedoso y de naturaleza híbrida pero autónoma dentro del sistema, que posee un gran número de cualidades a la hora de afrontar una renovación del anquilosado modelo de justicia español. El interés social de la mejora en la eficacia, impulsado por los principios de celeridad y de economía en el ámbito judicial, impacta de lleno en la consideración de esta institución como clave para el desarrollo del ámbito ejecutivo en el área contencioso-administrativa $^{1}$.

Desde una perspectiva formal, podemos decir que la mayoría de las veces se buscan soluciones procesales más allá del propio ordenamiento cuando, si profundizamos un poco en las instituciones, vemos que el legislador ya ha encontrado problemas y ha intentado buscarles solución. Este es el caso de la figura objeto de este estudio, que pretende hacer frente a la pluriincidencia procesal sobre una misma cuestión o ámbito dentro del orden contenciosoadministrativo.

¿Quién no es consciente de la importancia de un derecho fundamental como es la igualdad a la hora de un enjuiciamiento? Esta ha sido una preocupación constante para todos los operadores jurídicos. Sin embargo, la mayoría desconoce u olvida que, en sede de ejecución de sentencias, existe en el orden contencioso-administrativo un sistema habilitante de un título

${ }^{1}$ Como indica el Consejo General del Poder Judicial, los justiciables demandan una justicia predecible, equitativa y rápida. Vid. CGPJ - Estimación de los tiempos medios de los asuntos terminados (consulta en abierto: http://www.poderjudicial.es/cgpj/es/Temas/ Estadistica-Judicial/Estadistica-por-temas/Actividad-de-los-organos-judiciales/Estimacion-de-los-tiempos-medios-de-los-asuntos-terminados/, consultado el 18 de julio de 2019). 
ejecutivo basado en la identidad ${ }^{2}$. Este sistema, regulado con cierta cautela (en palabras de la propia Exposición de Motivos de la Ley 29/1998, de 13 de julio, reguladora de la Jurisdicción contencioso-administrativa, en adelante LJCA) permite la extrapolación de lo enjuiciado en un pleito anterior a sujetos no partes, ampliando de esta forma los límites de la cosa juzgada y revelando, por tanto, unas nuevas líneas para el derecho procesal. Se trata de una introducción de elementos declarativos en una fase posterior como es la ejecutiva. Sin duda, estamos ante uno de los avances jurídico-formales más olvidados de los últimos años.

Así, la pretensión de este trabajo no es otra que exponer los orígenes y fundamentar (desde la perspectiva procesal) una institución ciertamente abandonada, que puede ser capaz de lograr mejoras en el seno de una de las jurisdicciones más saturadas de la Administración de Justicia y, también por qué no, en los órdenes restantes. No debe olvidarse que, de un tiempo a esta parte, estamos asistiendo cada vez más a un fenómeno de masificación social, influenciado en gran medida por las plataformas digitales ${ }^{3}$. Por ello, una figura dedicada al tratamiento judicial de las masas debe recibir una atención más intensa de la que ha tenido tradicionalmente. Es ahora, cuando la individualidad va perdiendo terreno, el momento en el que una institución de estas características ha de ocupar un puesto relevante dentro del ordenamiento jurídico. La importancia del concepto de multitud en el siglo XXI ve su impacto en la regulación legal y, por ende, en nuestros Tribunales de Justicia. Hacer frente de manera amplia y conjunta no es ya una opción, sino que se ha convertido en una necesidad real del sistema judicial para poder ofrecer una respuesta jurídica rápida, igualitaria y eficaz ${ }^{4}$.

${ }^{2}$ El desconocimiento es bastante generalizado, ya que ni siquiera es un elemento que aparezca en las estadísticas judiciales por materias que gestiona el CGPJ y que pueden consultarse en http://www.poderjudicial.es/cgpj/es/Temas/Estadistica-Judicial/ .

${ }^{3}$ El desvelo por el impacto del poder de las masas en la sociedad fue una constante durante todo el siglo XX, y ha perdurado hasta la actualidad. Por ejemplo, vid. ORTEGA Y GASSET, J., La rebelión de las masas (edición de HERNÁNDEZ SÁNCHEZ, D.), Madrid, 2012 o CIVERA MARTÍNEZ, M. y ABAD CARRETERO, L., En pos de un nuevo Humanismo, Santander, 2018.

${ }^{4}$ La preocupación acerca de la masificación de este orden jurisdiccional viene de lejos y, aún hoy, sigue siendo una cuestión prioritaria al afrontar los problemas judiciales de nuestro país. Aquí hemos hecho referencia a la masificación con carácter general. Para más información acerca de las razones de la masificación en al ámbito contencioso-administrativo puede consultarse: DE DIEGO DÍEZ, L.A., Extensión de efectos y pleito testigo en la Jurisdicción Administrativa, Cizur Menor (Navarra), 2016, pp. 21 y ss., PÉREZ ANDRÉS, A.A., Los Efectos de las Sentencias de la Jurisdicción Contencioso-Administrativa, Elcano (Navarra), 2000, pp. 250 y ss., o CORDERO LOZANO, F., «La extensión de los efectos de la sentencia a terceros; un nuevo reto jurisdiccional» en Administración de Andalucía: revista andaluza de Administración Pública, núm. 47, 2002, pp. 113 y ss. 


\section{ANTECEDENTES HISTÓRICOS}

La cuestión de la igualdad y su tratamiento entre los administrados ha estado siempre muy presente en el ámbito contencioso. Ya la Ley de 13 de septiembre de 1888 sobre el ejercicio de la jurisdicción contencioso-administrativa reconocía en su artículo segundo in fine una legitimación para casos idénticos 5 . Un hecho que ha pasado desapercibido para los distintos estudios histórico-procesales, pero que marca la tendencia legislativa (y, en su caso, jurisprudencial) de luchar por el respeto de la identidad y la similitud en los procedimientos judiciales de este orden. Podemos decir que esta idea, junto al tratamiento que ha de recibir un tercero afectado por el acto o disposición en conflicto, son los pilares básicos sobre los que se construye la figura que estamos tratando, teniendo en cuenta el principio general de la eficacia inter partes de las resoluciones judiciales $\mathrm{y}$, como no, el respeto al derecho fundamental a la tutela judicial efectiva reconocido en el art. 24 de la Constitución Española (en adelante, CE).

Durante el siglo XX, en España, para el orden jurisdiccional contenciosoadministrativo se han promulgados dos leyes reguladoras. ¿Cómo han ido integrando esta figura en sus disposiciones? Al principio, la mencionada eficacia inter partes era un axioma inamovible. Sin embargo, el paso de los años y las distintas experiencias fueron demostrando que la conjugación de esta máxima con el tratamiento igualitario hacia los terceros afectados por el mismo acto o resolución era una acción positiva y eficaz, aunque no exenta de polémica.

La Ley de 27 de diciembre de 1956, reguladora de la Jurisdicción Contencioso-Administrativa dejaba claro en su art. 86 que las sentencias solo producirían efectos entre las partes del proceso ${ }^{6}$, salvo las que fuesen estimatorias

5 Vid. Gaceta de Madrid de 14 de septiembre de 1888 (Año CCXXVII-núm. 258, Tomo III, pp. 773).

${ }^{6}$ La doctrina avalaba esta posición al considerar que si se entendía que todas las sentencias eran susceptibles de eficacia general, perdería todo el sentido la eficacia inter partes. Vid. por ejemplo: CALVO DÍAZ, G., «Extensión de efectos de las sentencias dictadas por los Tribunales de la Jurisdicción Contencioso-Administrativa. Comentario al artículo 86.2 de la Ley de la Jurisdicción Contencioso-Administrativa», en Actualidad Administrativa, 1991, núm. 30, p. 380.

De todas formas, los afectados eran únicamente los directamente afectados por ese acto impugnado, excluyendo así otros similares, parecidos o idénticos pero independientes del acto anulado (Cfr. CUERNO LLATA, J.R., «Extensión de efectos de las sentencias dictadas por los Tribunales de la Jurisdicción Contencioso-Administrativa», en Revista de Estudios Locales CUNAL, El Consultor de los Ayuntamientos y de los Juzgados, 1998, núm. 22, p. 69).

Como indica la STS 1278/1996, de 29 de febrero, esta excepción se justificaba porque no tenía sentido que, declarada la nulidad de una disposición o un acto administrativo en 
de pretensiones anulatorias de actos o disposiciones, que también extendían su eficacia a las personas que estuviesen afectadas por ellos ${ }^{7}$. Esta afirmación ya abría un camino dentro de la eficacia clásica, al considerar que las anulaciones sí debían tener un estatus extensivo ${ }^{8}$, pero siempre de connotación subjetiva. Ha de afirmarse, por tanto, que la anulación era generalizada frente al reconocimiento de plena jurisdicción que tenía un carácter individualizado?

virtud de sentencia firme, se ejerciera una nueva pretensión anulatoria por un tercero cuando ya el acto que se trataba de impugnar había desaparecido de la realidad jurídica.

${ }^{7}$ La cualidad de las personas afectadas (quiénes eran éstas etc.) también suscitó dudas. Vid. por ejemplo: FONT I LLOVET, T., «la extensión a terceros de los efectos de la sentencia en vía de ejecución», en Justicia Administrativa: Revista de Derecho Administrativo, $\mathrm{n}^{\circ}$ extraordinario de 1999, p. 168.

${ }^{8}$ Vid. por ejemplo: STS 1445/1994, de 4 de marzo, FJ $2^{\circ}$ (En la misma línea; STS 1278/1996, de 29 de febrero, FJ 6º). Más profunda es la reflexión de la STS 9685/1995, de 4 de marzo $\left(\mathrm{FJ}^{\circ}\right)$, donde ya se expone la cuestión de la posible extensión de la cosa juzgada:

«Debemos, pues, analizar los elementos objetivos y subjetivos de aquel litigio para decidir en consecuencia, ya que si bien los términos del precepto contenido en el art. 86.2 de la Ley de esta Jurisdicción, resultan claros cuando se anula por sentencia una disposición de carácter general, al extender la eficacia de la cosa juzgada no sólo a las partes litigantes sino a las demás personas afectadas por la disposición anulada, lo que permite afirmar que la sentencia produce efectos erga omnes, sin embargo no aparece el contenido del indicado precepto tan evidente cuando la sentencia anula los actos administrativos, y de aquí que alguna doctrina (Sentencia de 4 de mayo de 1977 -Aranzadi 1956) haya distinguido entre la ampliación de los límites subjetivos de la cosa juzgada material y la extensión objetiva de lo resuelto en la sentencia, para concluir que no es posible ampliar ésta en perjuicio de las partes más allá de lo que fue objeto de la pretensión procesal acogida en la parte dispositiva.

Según esta tesis, la sentencia firme, pronunciada por el Tribunal indicado, no tendría otra eficacia que la de haber anulado el acto administrativo concreto impugnado en el recurso contencioso- administrativo al que puso fin. No obstante, la jurisprudencia consolidada de esta Sala ha declarado que los efectos erga omnes de las sentencias anulatorias de los actos administrativos no dependen de la pretensión deducida sino del contenido de la propia sentencia, de manera que su anulación alcanza a quienes se encuentren en la misma situación que los recurrentes aunque ello no posibilite el reconocimiento de situaciones jurídicas individualizadas (Sentencias de 9 de diciembre de 1983 - Aranzadi 6.148 -, 4 de diciembre de 1981 - Aranzadi 4.837 - y 17 de agosto de 1984 de la antigua Sala Quinta del Tribunal Supremo), llegando a afirmarse que el efecto erga omnes de la anulación del acto administrativo provoca la extinción de los procesos iniciados por otras personas contra el mismo acto en virtud de la satisfacción extraprocesal de la pretensión (Sentencias de esta Sala del Tribunal Supremo, de 3 de julio de 1991; 12 de febrero de 1992 y 1 de junio de 1992)».

9 Como ejemplo, por todas, traemos aquí los Considerando núm. 2 y 3 de la STS de 4 de diciembre de 1981 ( $\mathrm{n}^{\circ}$ Aranzadi 4837), que refleja muy claramente el sentido del art. 86.2 de la Ley de 1956:

"Que de conformidad con lo dispuesto en el artículo 86-2 de la Ley Jurisdiccional, las Sentencias que anulen el acto o la disposición recurridos producen 


\section{Se respetaban así los límites subjetivos del proceso $^{10}$.}

efecto no solo entre las partes, sino también respecto de las personas afectadas por los mismos, de cuyo precepto se desprende el poder expansivo de las Sentencias anulatorias en los procesos contencioso- administrativos, mediante el cual extienden sus efectos a terceros que se encuentran, respecto al acto o disposición anulados en idéntica situación que los recurrentes, amparando por tanto intereses legitimos situados fuera del área del litigio, según declaró la Sentencia de 21de abril de 1961, reiterada por las de 22 de septiembre de 1967 y las que en ella se citan, 16 de junio de 1969, 25 de abril de 1971 y 26 de enero de 1973, habiendo expresado la de 23 de marzo de 1979, que la sentencia produce efectos generales "erga omnes» y por tanto el pronunciamiento de la misma es vinculante para los afectados por dicha resolución, de cuyo principio se deduce la ampliación de los límites subjetivos del anterior pronunciamiento, a quienes sin haber sido parte en el proceso en que se dictó se encuentren afectados por los actos recurridos, de tal manera que puedan acogerse a los efectos favorables del mismo y en igual forma a como se resuelve en la expresada sentencia respecto a los que alli litigaron.

Que admitiendo la Administración esta doctrina no accede a las pretensiones de los aquí recurrentes, por estimar que el asunto está prejuzgado negativamente, por una de las dos sentencias que se ejecuta, la de 28 de septiembre de 1977, relativa a los Letrados, al expresar en uno de sus Considerandos «que la eficacia positiva de cosa juzgada de las Sentencias contencioso-administrativas anulatorias del acto o disposición recurridos declarada en el artículo 86-2 de la Ley Reguladora, no comprende al reconocimiento del derecho jurisdiccional individualizado pretendido por los litigantes, como consecuencia de aquella previa anulación que no es dable a quienes no han sido parte en el proceso, alterando los limites subjetivos de éste...».

Sin embargo la STS continúa exponiendo las razones en el Considerando $n^{\circ} 4$ :

"Que este razonamiento que no está recogido en la Sentencia de 26 de septiembre de 1977, sobre los Veterinarios, no tiene la transcendencia negativa que le confiere la Administración, sino que su significado es el de que no procedía pronunciarse en la Sentencia sobre la situación jurídica individualizada de quien no habia sido parte en el pleito, afirmación acorde con los límites subjetivos del proceso en virtud de los cuales sólo puede ventilarse con las partes intervinientes en el mismo, pero que no cercena los efectos «erga omnes» de la Sentencia anulatoria, pues como declaró la Sentencia de esta Sala de 16 de junio de 1969, «tal efecto no se extiende directamente al reconocimiento de las situaciones jurídicas individualizadas de los que no fueron parte en el proceso, las que deberán ser objeto de atención por la Administración al llevar a puro y debido efecto la Sentencia, adoptando/las medidas adecuadas a la respectiva situación de los demás afectados por la anulación, que si no obtienen de oficio o a su instancia el reconocimiento procedente como consecuencia del fallo, podrá interponer otros procesos, previa solicitud de la extensión a su favor de lo resuelto jurisdiccionalmente», siendo es te el sentido que hay que darle al razonamiento de la Sentencia de 28 de septiembre de 1977 y en ningún supuesto el de estimar que en ella se resolvía para el futuro sobre los derechos de los que no habiendo sido litigantes en el pleito resultaba afectados por la sentencia dictada en el mismo.»

${ }^{10}$ De hecho, DE LA OLIVA SANTOS, A. (Sobre la cosa juzgada: civil, contencioso-administrativa y penal, con examen de la jurisprudencia del Tribunal Constitucional, 
Como indicó CALVO DÍAZ, las dos cuestiones a las que había que atender eran, sin duda, la naturaleza de la pretensión de la sentencia originaria y la clase de acto o disposición impugnada ${ }^{11}$. No obstante, un sector doctrinal entendía que la anulación extensiva implicaba también los derechos o pretensiones que hubieran derivado de dicha anulación ${ }^{12}$, pero no así los derechos subjetivos reconocidos al actor originario. Los terceros que por obra de esta vis extensiva de la anulación se veían beneficiados, si la Administración no actuaba de oficio, debían acudir a la vía administrativa para hacer efectivos los derechos derivados de la misma. Si en vía administrativa veían denegada su pretensión o no recibían respuesta, tenían que instar un nuevo proceso contencioso-administrativo ${ }^{13}$.

Es cierto que, en su momento, se abrió un gran debate (tanto a nivel doctrinal como jurisprudencial) debido a la confusión entre los límites de la cosa juzgada y los efectos jurídico-materiales de las anulaciones ${ }^{14}$. Así, como expone ROSENDE VILLAR, existían dos corrientes doctrinales enfrentadas, basadas en el texto literal del art. 86.2 de la antigua Ley: por un lado, los defensores de la extensión de la cosa juzgada por disposición legal y, por otro, los partidarios de la propia eficacia jurídico-material de las sentencias constitutivas ${ }^{15}$.

Madrid, 1991, p. 134) llega a afirmar que, a su juicio, tanto la dicción literal del art. 86.2 LJCA como la naturaleza misma de la sentencias que reconocen situaciones o derechos individualizados imponen, en principio, una respuesta contraria a extender a terceros no litigantes la eficacia de cosa juzgada.

${ }_{11}$ Vid. CALVO DÍAZ, G., «Extensión de efectos de las sentencias dictadas por los Tribunales de la Jurisdicción Contencioso-Administrativa...», ob. cit., p. 379. En la actualidad, esta afirmación sigue plenamente vigente.

${ }_{12}$ Por ejemplo: vid. XIOL RÍOS, J.A., «Consideración de algunos aspectos del proceso administrativo como respuesta a los fenómenos de masificación social: la legitimación, la limitación de las instancias, el tratamiento en serie de los recursos y los efectos de la sentencia», en «Jurisdicción contencioso-administrativa: aspectos procesales», Cuadernos de Derecho judicial, Madrid, Consejo General del Poder Judicial, 1992, XV, p. 188 o QUINTANA REDONDO, C. et al., Comentarios a la Ley de lo Contencioso-Administrativo, Madrid, 1965, vol. II, p. 509.

${ }_{13}$ En esta época, más que una extensión de efectos propiamente dicha podemos ver que se configuraba un precedente judicial que, en cierto grado, debía ser respetado por los Tribunales debido a los efectos positivos de la cosa juzgada material. Dicho de otro modo, los terceros no partes del proceso pero beneficiados por uno anterior no podían utilizar la sentencia originaria como título ejecutivo de forma directa.

${ }_{14}$ Vid. DE LA OLIVA SANTOS, A., Sobre la cosa juzgada: civil, contencioso-administrativa y penal..., ob. cit., pp. 127 y ss.

${ }^{15}$ Cfr. ROSENDE VILLAR, C., La Eficacia Frente a Terceros de las Sentencias Contencioso-Administrativas, Cizur Menor (Navarra), 2002, p. 118. Puede verse además todo el recorrido jurisprudencial a favor y en contra de esta técnica jurídica. Ibíd., pp.118 y ss. En igual sentido: VEGA CASTRO, J.L., «La extensión a terceros de los efectos de 
A pesar de los mencionados antecedentes, esta situación ve un cambio radical con el impacto del Auto del Tribunal Supremo de 29 de Noviembre de 1985. Las interpretaciones jurisprudenciales con sus proyecciones extensivas modificarán el sentido de la norma contenida en el art. 86 de la antigua Ley, poniendo la semilla del nuevo sistema y abriendo la posibilidad de reconocer a terceros no partes en el proceso situaciones jurídicas individualizadas $^{16}$. De todas formas, será una introducción paulatina que, como hemos visto ut supra con las sentencias de la década de los noventa del pasado siglo, no gozará de una gran repercusión a nivel jurisprudencial. Esta nueva figura se incorporará a partir de 1998 en el ordenamiento contencioso-administrativo y, concretamente, en el art. 110 LJCA.

¿Cómo pudo el Alto Tribunal ampliar la eficacia de la cosa juzgada material? La forma de hacerlo fue la personación en la fase de ejecución de sentencias, con base en el mencionado Auto. Sin embargo, como indicaban algunos autores, tal personación era admisible para la reiteración de la nulidad ya declarada con carácter general, pero no para reconocer derechos con$\operatorname{cretos}^{17}$. No debe olvidarse que la fase de ejecución de sentencias no tenía por

las sentencias dictadas por los Tribunales de la Jurisdicción Contencioso-Administrativa en el seno de la vía de ejecución: una solución problemática», en AAVV., La Justicia Administrativa, Barcelona, 2003, p. 909.

${ }^{16}$ Como indica PÉREZ ANDRÉS, A.A., Los Efectos de las Sentencias..., ob. cit., p. 255: «El Auto que comentamos se inclinó por la posibilidad de que la negativa de la Administración fuese impugnada directamente en vía de ejecución de la sentencia modelo, ante la Sala que fuera competente.»

17 Vid. por ejemplo: CALVO DÍAZ, G., «Extensión de efectos de las sentencias dictadas por los Tribunales de la Jurisdicción Contencioso-Administrativa...», ob. cit., pág. 382.

De hecho, como recuerda la STS 57/2017 de 11 de enero, FJ $2^{\circ}$ :

«El principio de legalidad exige que los actos administrativos se ajusten al ordenamiento jurídico, permitiendo que la Administración revise los actos ilegales. Por el contrario, la seguridad jurídica, en cuanto valor esencial de nuestro ordenamiento jurídico, exige que los actos administrativos dictados, y consiguientemente las situaciones por ellos creadas, gocen de estabilidad y no puedan ser revisados fuera de determinados plazos. Ahora bien, cuando la ilegalidad del acto afecta al interés público general, al tratarse de infracciones especialmente graves, su conservación resulta contraria al propio sistema, como sucede en los supuestos de nulidad de pleno derecho, por lo que la revisión de tales actos no está sometida a un plazo para su ejercicio (art. 102 de la Ley 30/1992).

La declaración de nulidad queda limitada a los supuestos particularmente graves y evidentes, al permitir que el ejercicio de la acción tendente a revisar actos que se han presumido validos durante un largo periodo de tiempo por sus destinatarios pueda producirse fuera de los plazos ordinarios de impugnación que el ordenamiento establece.(...)»

Como vemos, el acto administrativo podía y puede ser declarado nulo de pleno derecho en cualquier momento, con lo que sus efectos dejaran de tener eficacia en vía admi- 
esas fechas (ni tiene en la actualidad) como objeto el ámbito declarativo, por lo que su uso no puede abarcar todas las facultades del proceso ${ }^{18}$.

El FJ $5^{\circ}$ de este Auto de 1985 contiene lo que podemos llamar el germen de la extensión de efectos como figura procesal individualizable. Así expone:

«(...) Si la Administración no reconoce los efectos del art. 86.2 de la Ley Jurisdiccional, no hay que seguir un nuevo proceso contencioso-administrativo, lo cual haría poco operativa dicha norma, sino que frente a la negativa, los afectados pueden conforme a los arts. 103 y siguientes de la citada Ley, insertarse dentro de la fase ejecutiva del proceso anterior, para que los efectos de la sentencia les alcancen.»

Podemos comprobar que, a diferencia de lo que ocurría desde 1956, donde el potencial reconocimiento de efectos era, para la jurisprudencia favorable, inmediato por las características de las anulaciones, a partir de este Auto son los interesados afectados de forma directa pero no partes en el proceso, los que han de personarse para que se les aplique la extensión y, además, se les reconozcan situaciones jurídico-individualizadas. Cambia el paradigma procesal, pues aquí se utiliza un elemento de la fase declarativa en el momento de la ejecución de una sentencia anterior.

En nuestra opinión, el Tribunal Supremo en 1985 dio un paso más. Mientras que las interpretaciones anteriores se basaban en el principio de igualdad y su finalidad era el respeto al mismo en el mayor grado posible, aquí el Tribunal ya busca lograr la eficiencia y considera innecesario el comenzar un nuevo proceso desde el origen. No puede negarse que, a nivel creativo, se trata de un hecho relevante para toda la materia procesal del ámbito contencioso. De hecho, esta interpretación que el Tribunal Supremo concedió al art. 86 de la antigua Ley, puede ser considerada como precursora de las nuevas líneas de gestión de los recursos en materia judicial, pues ponía el acento ya en la poca operatividad de llevar a cabo reiteraciones en casos idénticos, llegando incluso

nistrativa, pero pasar de esta situación a la contraria y ya en vía judicial, es decir, reconocer efectos erga omnes a una sentencia que reconocía situaciones jurídicas dictada inter partes vía jurisprudencial sin establecerse legalmente era, como indica esta autora, ir demasiado lejos.

${ }^{18}$ Esta afirmación conforma en nuestra opinión uno de los fundamentos de la naturaleza de la figura comprendida en el art. 110 LJCA. De hecho, CALVO DÍAZ, G. («Extensión de efectos de las sentencias dictadas por los Tribunales de la Jurisdicción Contencioso-Administrativa...», ob. cit., p. 383) llega a expresar que: «la consecuencia es que tal contenido limitado hace imposible incardinar, en esta fase, el juicio de subsunción de aquellos sujetos que se dicen afectados por la sentencia en el supuesto de hecho que ha dado lugar a ella, labor ésta de confrontación de la sentencia en cuestión con la petición de los que se dicen afectados, que excede completamente del contenido propio de la fase de ejecución y que resultaría, al mismo tiempo, imprescindible para reconocer o no los efectos cuya extensión se solicita.» 
a reconocer la efectividad de los derechos enjuiciados ${ }^{19}$. Desafortunadamente, la novedosa situación creada a partir del citado Auto de 1985 no durará mucho, pues de nuevo se alzarán voces contra el carácter extensivo y de consideración amplia de las anulaciones, siendo su máximo exponente la STS 1278/1996, de 29 de febrero, donde se alude a una idea que aún hoy sigue presente: la falta de sustantividad propia del incidente de ejecución de sentencias para poder reconocer situaciones jurídicas individualizadas ultra partem ${ }^{20}$.

La LJCA de 1998 recogerá este testigo y establecerá en su articulado todo un sistema de extensión ultra partem de los efectos de las sentencias, dando un paso al frente en la sistemática procesal contencioso-administrativa. Este mecanismo no estará exento de críticas, siendo incluso cuestionada su denominación.

\section{FUNDAMENTOS DE LA FIGURA}

En el caso de la extensión de efectos de sentencias firmes podemos distinguir entre varios tipos de causas por las cuáles esta herramienta procesal toma forma. Podría parecer que no tiene sentido plantear una clasificación de las razones que fundamentan la institución, ya que éstas se encuentran en planos distintos y responden a necesidades concretas según la perspectiva que analicemos. No obstante, como medio para facilitar la comprensión de las mismas podemos sistematizarlas de manera global por la proyección del impacto que producen, puesto que encontramos aspectos o razones que benefician al Estado en general, otras que se centran más en el ámbito propio del ciudadano e, incluso, algunas bases que únicamente son de carácter técnicoprocesal.

${ }_{19}$ No obstante, algunas líneas jurisprudenciales aún seguían reconociendo un cierto papel prevalente de la Administración. Lo podemos ver en el ATS 322/1997, de 31 de julio (FJ $2^{\circ}$ ):

«(...)La consecuencia que cabe extraer no es otra que, en todo caso, y aun siendo indiscutible el efecto erga omnes que reconoce el repetido art. 82.6 a toda Sentencia anulatoria de un acto administrativo en este orden jurisdiccional, procede previamente brindar a la Administración la oportunidad de realizar los actos oportunos para lograr todas las consecuencias inherentes a la anulación de sus actos respecto de los interesados a que se refiere el aludido precepto, mediante la correspondiente petición en vía administrativa, sin perjuicio de recurrir en su caso al ulterior cauce procesal jurisdiccional para la efectividad de los derechos que brinda este artículo a quienes no han sido parte en el proceso.»

${ }_{20}$ Para una mayor comprensión del recorrido histórico de la figura puede consultarse la STS 5470/2007, de 19 de julio, que muestra el iter evolutivo de la extensión de los efectos a terceros no partes a partir de la inclusión del art. 86.2 de la Ley de 1956. ¿Realmente la extensión de efectos es un incidente de ejecución? La naturaleza jurídica de esta figura aún hoy sigue sin definirse categóricamente. 
En relación con la clasificación citada, puede decirse que la extensión de efectos de sentencias firmes repercute en la paz jurídico-social del Estado, en el sentido de que otorga un mecanismo de tutela judicial que favorece un mejor funcionamiento de la Administración de Justicia y, además, tiende a evitar las contradicciones judiciales. Por otro lado, la esfera personal del ciudadano que se enfrenta a la Administración también mejora, en tanto que se acortan los plazos y los gastos.

\section{Clasificación de los fundamentos}

La extensión de efectos de sentencias firmes tal como la conocemos surge a raíz de una serie de interpretaciones jurisprudenciales y doctrinales más aperturistas de la eficacia inter partes de las sentencias que, por motivos de ahorro temporal y agilización en el funcionamiento de los Tribunales, permitieron su posterior reconocimiento legal. Es evidente que, como indica la Exposición de Motivos de la LJCA y acepta la mayoría de los autores, la finalidad del art 110 LJCA es la de evitar la multiplicación de procesos sobre idénticas situaciones jurídicas en las materias reservadas ${ }^{21}$. Sin embargo, debe profundizarse en las razones que subyacen a esta afirmación. Hemos comentado ut supra que no puede plantearse una clasificación estándar de carácter temporal ni tampoco en función de su importancia, ya que todas las razones que han fundamentado la extensión de efectos se han ido superponiendo a lo largo del tiempo, y su relevancia dependerá de la valoración que se pretenda obtener. De hecho, la doctrina incluso mezcla los distintos fundamentos porque, obviamente, están fuertemente interconectados ${ }^{22}$. Además, como en muchos otros ámbitos, se produce la paradoja de que las bases de la institución se confunden con sus objetivos o finalidad.

De todas formas, con estas premisas, podemos distinguir distintos grupos de razones que analizaremos a continuación.

\subsection{Razones que cimentan la extensión de efectos en el ámbito general}

La LJCA en el art. 110 otorga un plus de tutela (en el sentido de poder obtener una resolución más abreviadamente) a ciertas materias cuando se

${ }^{21}$ Por ejemplo, ROMERO REY, C., en QUINTANA CARRETERO, J.P., (dir.), Comentarios a la Ley de la Jurisdicción Contencioso-Administrativa, Valladolid, 2013, p. 767, es claro: «el art. 110 tiene por finalidad evitar la multiplicación de procesos sobre idénticas situaciones jurídicas en materia tributaria y de personal al servicio de la Administración Pública» (A lo que actualmente habría que añadir la materia de unidad de mercado).

${ }^{22}$ Los fundamentos de la extensión de efectos no han sido un tema muy recurrente para la doctrina, que se ha limitado, en la mayoría de los casos, a aceptar ope legis la figura. 
cumplen unos requisitos concretos, con base en la identidad de situaciones. Así, la principal razón material que fundamenta la extensión de efectos es, a nuestro parecer, el principio de igualdad ante la Ley y, expresamente en su aplicación ${ }^{23}$. Como indica ROSENDE VILLAR ${ }^{24}$ : «la ley determina (...) no tanto que los órganos judiciales dispensen necesariamente un mismo trato jurídico a los que se hallan en idéntica situación, sino más bien que situaciones iguales no sean juzgadas de un modo distinto injustificadamente».

De igual manera, y al hilo con lo anterior, podemos decir que el ordenamiento jurídico se ve beneficiado en tanto que se amplía la efectividad de la tutela judicial contenida en el art. $24 \mathrm{CE}^{25}$, principalmente en su vertiente de acceso a la jurisdicción, pues se abren dos caminos: por un lado, el proceso ordinario contencioso-administrativo y, por otro (únicamente para las materias reservadas), la extensión de efectos de sentencias ${ }^{26}$. De hecho, PÉREZ DEL BLANCO, considera que la extensión de efectos agiliza la satisfacción del derecho a la tutela jurisdiccional en los supuestos donde la única variación de su otorgamiento sea el sujeto que se hace acreedor de la misma $^{27}$.

Sin embargo, cuando se analiza la perspectiva que el Tribunal Constitucional otorga a este derecho ${ }^{28}$, vuelve a surgir la duda acerca de si su

${ }^{23}$ No obstante, DE MIGUEL PAJUELO, F., «La extensión A Terceros de los Efectos de la Sentencia», en PALOMAR OLMEDA, A. (dir.) et al., Tratado de la Jurisdicción Contencioso-Administrativa, Cizur Menor (Navarra), 2012, p. 932 entiende que el principio de igualdad ante la ley es el fundamento únicamente del requisito de la necesaria identidad entre las situaciones.

${ }^{24}$ Cfr. ROSENDE VILLAR, Cecilia, La Eficacia Frente a Terceros..., ob. cit., p. 170.

${ }^{25}$ Poco tiempo después de la entrada en vigor de la LJCA, LÓPEZ BENÍTEZ, M., («Comentarios a la Ley de la Jurisdicción Contencioso-Administrativa de 1998», en Edición especial del núm. 100, Revista Española de Derecho Administrativo, 1999, p. 780) afirmaba acerca de la extensión de efectos lo siguiente: «(...) La LJCA salda así, por vía legislativa, la titubeante posición que, al respecto viene manteniendo la jurisprudencia del Tribunal Supremo, y da satisfacción a una necesidad hondamente sentida por nuestra doctrina y que afecta de manera relevante a la efectividad del derecho a la tutela judicial».

${ }^{26}$ No se produciría una vulneración del derecho de defensa porque a los primeros recurrentes o recurrentes originarios se les concede trámite de audiencia.

${ }^{27}$ Cfr. PÉREZ DEL BLANCO, G. «La extensión subjetiva de los efectos de las sentencia administrativa en los supuestos de litigios en masa», en CEFLegal, Junio, 2005, núm. 53, p. 88.

${ }^{28}$ Como podemos ver en la STC 182/2002, de 14 de octubre:

«Este Tribunal ha declarado reiteradamente, desde nuestra temprana sentencia del Tribunal Constitucional 19/1981, de 8 de junio, que el derecho a la tutela judicial efectiva reconocido en el artículo 24.1 de la Constitución Española comprende primordialmente el derecho de acceso a la jurisdicción, es decir, el derecho a provocar la actividad jurisdiccional que desemboque en una decisión judicial (entre otras, sentencias del Tribunal Constitucional 115/1984, de 3 de 
verdadero carácter no es otro que el carácter administrativo previo a la vía judicial (como se manifestaba en la redacción original del art. 110 LJCA), en tanto que no se está provocando a la autoridad judicial para que decida, sino que se solicita una asimilación de una previa resolución por igualdad; el solicitante solo tiene que justificar las razones de la identidad de situaciones tanto fácticas como jurídicas. Así, MENÉNDEZ PÉREZ incluso expresa que ni siquiera es necesario que el tercero ejerza la acción judicial ${ }^{29}$ y PENDÁS GARCÍA manifiesta que es el propio modus operandi de la Administración (que resuelve muchos expedientes idénticos con una misma resolución) el que fundamenta la previsión legal del art. $110 \mathrm{LJCA}^{30}$. Esta postura es manifiestamente contraria a otra de las cuestiones que surgen con relación a la extensión de efectos: si, realmente, la función del juzgador en ella forma también parte de la potestad del art. 117.3 CE de juzgar y hacer ejecutar lo juzgado que le corresponde en exclusiva a los Tribunales. Nuestra opinión es afirmativa, ya que podemos decir que se lleva a cabo un desplazamiento del enjuiciamiento que ya se ha producido en un proceso anterior, por lo que únicamente el juez ha de comprobar la identidad de situaciones, pero haciendo ya una labor de valoración; la prueba fáctica es que resuelve a través de un auto. De nuevo, se vuelve a evidenciar la naturaleza híbrida y mixta de esta figura, por lo que debido a sus múltiples aristas es imposible su clasificación absoluta y así lo ha demostrado el legislador con los cambios que ha ido sufriendo el art. 110 desde 1998.

A la par, se ha planteado ante el Tribunal Constitucional la vulneración del art. $24 \mathrm{CE}$ en su vertiente del derecho a que las resoluciones judiciales sean ejecutadas en sus propios términos, puesto que en una extensión de efectos la Sala resolvió de forma contraria a lo que en su día dispuso para una recurrente anterior ${ }^{31}$. Este Tribunal ha sido claro y en su STC 146/2005, de 6 de junio entendió que no existe un derecho al acierto, ya que los derechos y

diciembre, FJ 1; 211/1996, de 17 de diciembre, FJ 2; 36/1997, de 25 de febrero, FJ 3; 132/1997, de 15 de julio, FJ 2), por lo que se erige en elemento esencial de su contenido el derecho a obtener de los Jueces y Tribunales una resolución razonada y fundada en Derecho sobre el fondo de las pretensiones oportunamente deducidas por las partes...». En el mismo sentido vid. STC 111/2009, de 11 de mayo $\left(\mathrm{FJ} 2^{\circ}\right)$.

29 Vid. MENÉNDEZ PÉREZ, S., en BAENA DEL ALCÁZAR, M. (dir.), Ley Reguladora de la Jurisdicción Contencioso Administrativa, Doctrina y Jurisprudencia, Madrid, 1999, p. 702.

${ }^{30}$ Cfr. PENDÁS GARCÍA, B. (coord.), Ley de la Jurisdicción Contencioso-Administrativa. Estudio sistemático, Barcelona, 1999, p. 396.

31 Para mayor información: vid. Cubillo López, Ignacio José. 2018. «El derecho a la tutela judicial efectiva y el derecho a la ejecución en la jurisprudencia constitucional». Estudios de Deusto 66, $\mathrm{n}^{\mathrm{o}}$ 2: 347-372. 
garantías del art. $24 \mathrm{CE}$ no garantizan la justicia de la decisión y tampoco la satisfacción de la pretensión de ninguna de las partes del proceso.

Otro de los aspectos del binomio tutela judicial efectiva-extensión de efectos de sentencias firmes que ha sido cuestionado es la constitucionalidad de la posibilidad casacional de los autos resolutorios de extensión de efectos. En este sentido, el Tribunal Supremo ha considerado que no puede entenderse vulnerado el art. $24 \mathrm{CE}$, puesto que el derecho al recurso es un derecho de configuración legal que no puede extralimitarse ${ }^{32}$.

32 Así lo expone, por ejemplo, el ATS 12524/2017, de 21 de diciembre: «El hecho de que la ley establezca la posibilidad de recurrir en casación las sentencias dictadas en única instancia por un juzgado unipersonal cuando sean susceptibles de extensión de efectos está justificada por la especialidad que representa el mecanismo previsto en el art. 110 de la LJ, al permitir que las sentencias en materia tributaria, de personal y unidad de mercado que hubieran reconocido una situación jurídica individualizada a favor de una o varias personas "pueda extenderse a otras, en ejecución de sentencia» si los interesados se encuentran «en idéntica situación jurídica que los favorecidos por el fallo». En definitiva, la posibilidad de extender los efectos de una sentencia favorable a otros muchos afectados, mediante un incidente de ejecución y sin necesidad de entablar un recurso autónomo en materias en las que existen potencialmente otros afectados en la misma situación, dota a estos pronunciamientos de un efecto multiplicador que trasciende del caso concreto y tiene la virtualidad de proyectarse sobre otros muchos, lo que tradicionalmente ha justificado que puedan tener acceso al recurso de casación los Autos dictados en aplicación del art. 110, tanto en el anterior régimen casacional (art. 87.2) como en el actual (art. 87.1.e). Estas sentencias trascienden, por su eventual fuerza expansiva, del caso singular enjuiciado, lo que justifica que la decisión adoptada pueda ser revisada en casación, impidiéndose así que una sentencia equivocada y gravemente danosa para los intereses generales tenga una fuerza expansiva de la que carecen los pronunciamientos que limitan sus efectos a un supuesto concreto. En este contexto se enmarca la previsión contenida en el art. 86.1 párrafo segundo. Es cierto que por el juego combinado de los artículos 86.1 y 100 de la LJ tan solo resultan recurribles en casación las sentencias de los juzgados unipersonales cuando, versando sobre determinadas materias, reconozcan una situación jurídica individualizada y, por ende, cuando sean estimatorias. También es cierto que, como regla general, la Administración ostenta la posición de parte demandada en el proceso judicial de instancia, por lo que será está y no el particular la que normalmente podrá recurrir en casación estas sentencias, ya que el particular, que ha visto satisfechas sus pretensiones, no tendrá interés legítimo en recurrir una sentencia que le es favorable.

Pero, esta previsión legal no introduce, como parece sostener el recurrente, una limitación subjetiva y discriminatoria en favor de la Administración y en contra de los particulares. La recurribilidad de la sentencia en casación no viene condicionada por razones subjetivas (particular o Administración) ni por la posición que cada una de estas partes ostentaba en la instancia. De hecho esta disposición opera también en los casos en los que la Administración actúa como parte demandante y el particular como demandado (como es el caso del recurso de lesividad), o en aquellos otros en los que un particular se persona como codemandado en la instancia. La razón que justifica estos asuntos pueda 
Para la doctrina, las razones que fundamentan la existencia de la extensión de efectos también son de carácter general pero de otra índole. Por ejemplo, para DE DIEGO DÍEZ ${ }^{33}$, la razón principal que hace surgir la extensión de efectos como la conocemos hoy en día es la masificación del orden contencioso-administrativo, debido a la creciente intervención pública en los distintos ámbitos sociales. En la misma línea, AGÚNDEZ FERNÁNDEZ ${ }^{34}$ entiende que los principios de economía procesal y tutela judicial efectiva hacen extensibles los pronunciamientos del fallo a los ciudadanos, evitándose nuevos procesos y haciendo más eficaz y eficiente la actuación de las Administraciones Públicas, tanto en beneficio de los intereses generales como de los particulares ${ }^{35}$. De la misma forma,

acceder al Tribunal Supremo es el eventual efecto expansivo y multiplicador que estas sentencias pueden tener para otros afectados que se encuentren en la misma situación, y, por lo tanto, por los efectos que pueden desplegar con los consiguientes perjuicios al interés general general. Y este efecto tan solo se produce en las sentencias estimatorias sobre determinadas materias, pues solo éstas pueden proyectar el pronunciamiento recaído en ese caso concreto sobre otros muchos afectados sin tener que entablar un recurso autónomo. De ahí que solo estas sentencias, con independencia de quien sea la parte recurrente, son las que tienen abierta la posibilidad de que el Tribunal Supremo revise, si el asunto presenta interés casacional objetivo, la conformidad o disconformidad a derecho del pronunciamiento emitido.

Por todo ello, este Tribunal no alberga dudas sobre la constitucionalidad de estos preceptos que le exija el planteamiento de una cuestión de inconstitucionalidad, al entender que regulación no resulta contraria al derecho a la tutela judicial efectiva ni introduce una diferenciación carente de justificación objetiva y razonable...» En la misma línea: ATS 7502/2018, de 25 de junio (FJ $2^{\circ}$ in fine).

${ }^{33}$ Vid. DE DIEGO DÍEZ, L.A., Extensión de efectos..., ob. cit., pp. 21 y ss. Este autor considera además que la LJCA ha tenido que responder al fenómeno de otorgar eficacia ultra partes a los fallos que reconocían situaciones jurídicas individualizadas a los miembros de un grupo, cuestión a la que la respuesta que otorgaba la Ley de 1956 era insuficiente.

En la misma línea se muestra CONTÍN TRILLO-FIGUEROA, E. («Extensión de los efectos de la sentencia en la Jurisdicción Contencioso-Administrativa», Revista Aragonesa de Administración Pública, núm. 32, Junio, 2008, p. 591) que expone: «la finalidad de estos preceptos es hacer frente a la situación de saturación del orden jurisdiccional contencioso-administrativo, que ha sufrido hasta el extraordinario el incremento de la litigiosidad, con el objeto de contribuir a aliviar y descongestionar el orden contenciosoadministrativo».

${ }^{34}$ Cfr. AGÚNDEZ FERNÁNDEZ, A. et al., El proceso Contencioso-Administrativo..., ob. cit., p. 887. En igual sentido, MENÉNDEZ PÉREZ, S., en BAENA DEL ALCÁZAR, M. (dir.), Ley Reguladora de la Jurisdicción Contencioso Administrativa, ob. cit., p. 703.

${ }^{35}$ Como ya adelantábamos, intentar clasificar las razones es una tarea difícil que, si bien simplifica en ciertos casos la comprensión de los fundamentos de la extensión, en 
SANTAMARÍA PASTOR ${ }^{36}$ considera que la técnica de la extensión de efectos permitiría ahorrar «un tiempo y esfuerzo extraordinario de los jueces y de sus respectivas oficinas judiciales».

GÓMEZ-FERRER MORANT matiza las opiniones anteriores, añadiendo el continuo cambio legislativo como razón por la cual se producen disposiciones generales y actos administrativos que son impugnados posteriormente mediante series interminables de recursos de idéntico objeto que dan lugar a una masificación de la justicia, lo que ha conllevado el surgimiento de mecanismos como el que estamos tratando en estas líneas ${ }^{37}$.

Asimismo, el papel de la seguridad jurídica es clave a la hora de analizar los fundamentos de la extensión de efectos. Como exponía DÍEZ-PICAZO ${ }^{38}$, la seguridad jurídica significa la previsibilidad de que los poderes públicos en un caso concreto, actuaran o dejarán de hacerlo, y de que, si actúan, lo harán de una manera concreta, por lo que puede determinarse como base de la extensión de sentencias firmes. También puede considerarse fundamento de la extensión el abaratamiento de los costes que ha de conllevar su uso, principalmente por el acortamiento del proceso. Esta es la opinión que mantiene MARTÍNEZ ALARCON, cuando entiende que con la extensión de efectos se ven beneficiados los principios de economía procesal y tutela judicial efectiva con el consiguiente abaratamiento de los costes económicos ${ }^{39}$.

\subsection{Razones que fundamentan la extensión para la esfera del ciudadano}

En nuestra opinión, los fundamentos de la extensión de efectos hay que buscarlos más en la implicación para la justicia que para el propio ciudadano, aunque éste se vea beneficiado por las mejoras de su ordenamiento jurídico en un plano directo. No podemos afirmar, por tanto, que la razón de ser de la extensión de efectos de sentencias firmes sea el beneficio de la ciudadanía, pues en ese caso, el legislador no habría limitado las materias (no olvidemos

otros casos como éste simplemente otorga una visión que se superpone en las dos esferas: general y particular.

${ }^{36}$ Cfr. SANTAMARÍA PASTOR, J.A., La Ley reguladora de la Jurisdicción Contencioso-Administrativa, Comentario, Madrid, 2010, p. 1149. No obstante, este autor considera que el nuevo mecanismo ha sido un fracaso y no ha otorgado beneficios para los litigantes que la han usado.

37 Vid. GÓMEZ-FERRER MORANT, R., «Artículo 111», en Revista Española de Derecho Administrativo no 100, 1998, p. 791.

${ }^{38}$ Cfr. DÍEZ PICAZO, L.M., «La doctrina del precedente administrativo», en Revista de Administración Pública, 1982, núm. 98, p. 13.

39 Vid. MARTíNEZ ALARCÓN, M., en MORENO MOLINA, J.A., (dir.) et al., Procedimiento y Proceso Administrativo Práctico (Vol. III, Proceso Contencioso-Administrativo), Madrid, 2006, p. 987. 
que la extensión de efectos solo puede producirse en asuntos de materia de personal al servicio de las Administraciones públicas, asuntos tributarios o de unidad de mercado) ni tampoco sería tan restrictivo a la hora de la presentación de una solicitud de estas características. Es indudable que el ciudadano se ve beneficiado al no tener que interponer un recurso ordinario, aunque, de todas formas, ha de iniciar un procedimiento ${ }^{40}$. A diferencia de lo que venimos manifestando, ciertos autores consideran que el fundamento de la extensión está en la mejora de la esfera jurídica ciudadana. Así, CORDERO $\mathrm{LOZANO}^{41}$ entiende que la innovación del art. 110 LJCA es, para el administrado, una respuesta ante los tradicionales privilegios que ha ostentado la Administración, principalmente a la hora de los plazos por el retardo de la justicia.

En otra línea se encuentra VEGA CASTRO. Para este autor el motivo del art. 110 LJCA es el de dar respuesta legal a la eficacia de las sentencias y sus consecuencias en los actos masa ${ }^{42}$, a lo que SENÉS MOTILLA añade el consiguiente ahorro tanto económico como temporal ${ }^{43}$.

FONT I LLOVET defiende que con la LJCA se produjo un cambio de funcionalidad en el orden contencioso-administrativo, donde el ciudadano

${ }^{40}$ CORDOBA CASTROVERDE añade una precisión interesante cuando entiende que el beneficio particular al ciudadano se cimenta en la posibilidad de que éstos no estarían obligados a recurrir de forma separada los actos administrativos que les afectasen de forma individual cuando se basaran en una misma fundamentación, bastando con que lo hiciera uno y tras esperar un pronunciamiento firme poder solicitar, por vía de ejecución de la sentencia, la extensión de los efectos de la misma. (Cfr. CÓRDOBA CASTROVERDE, D., en «Dificultades y problemas que plantea en la actualidad la extensión de efectos de las sentencias en el orden contencioso-administrativo», Revista de Jurisprudencia El Derecho núm. 4, Diciembre 2011, consulta en abierto: https://elderecho.com/dificultadesy-problemas-que-plantea-en-la-actualidad-la-extension-de-efectos-de-las-sentencias-enel-orden-contencioso-administrativo, consultado el 14 de julio de 2019).

${ }^{41}$ Vid. CORDERO LOZANO, F., «La extensión de los efectos de la sentencia a terceros en el artículo 110 de la LJCA; una reflexión», en Revista Aragonesa de Administración Pública, núm. 21, Diciembre, 2002, pp. 441 y ss.

${ }^{42}$ Vid. VEGA CASTRO, J.L., «La extensión a terceros de los efectos...», ob. cit., pp. 907 y 908. La misma opinión es la que manifiestan PERA VERDAGUER, F., Comentarios a la Ley de lo Contencioso Administrativo, Barcelona, 2004, p. 761 o HUERTA GARICANO, I. y DE LA CRUZ MERA, F., «La extensión de efectos como cauce alternativo a la interposición del recurso contencioso-administrativo», Foro Abierto», Revista de Jurisprudencia El Derecho, núm. 2, 2011, pp. 7 y ss.

${ }_{43}$ Vid. SENÉS MOTILLA, C., «La ejecución de las sentencias en la nueva Ley de la Jurisdicción contencioso-administrativa» en La Ley: Revista jurídica española de doctrina, jurisprudencia y bibliografía, 1998, núm.6, (D-323), p. 2263. En el mismo sentido, BLÁZQUEZ LIDOY, A., «La extensión de efectos de las sentencias en materia tributaria (art.110 de la LJCA)», en MERINO JARA, I. (dir.) et al., Estudios sobre el proceso contencioso-administrativo en materia tributaria, Barcelona, 2015, p. 790. 
pudo comprobar que ostentaba derechos frente a la Administración y que éstos recibían tutela por parte de los Tribunales, pero teniendo que hacer frente a una justicia lenta y desigual que propició el nacimiento de distintas figuras que mejoraron la efectividad y la protección de los derechos individuales de las cuales una representante ha sido la extensión de efectos del art. $110 \mathrm{LJCA}^{44}$. El fundamento que para este autor sirve de base de la creación del art. 110 LJCA está en la línea con los nuevos aires de mejora de la justicia que ha propugnado la Unión Europea.

Podemos observar, por tanto que, en esta corriente, la doctrina se sitúa en la postura de entender la extensión de efectos como un mecanismo que beneficia a los ciudadanos de forma directa a la hora de iniciar una solicitud de extensión de efectos, intentando con ella abreviar los plazos y también abaratar el coste judicial.

\subsection{Razones de carácter técnico}

Por último, podemos comprobar que una parte de la doctrina entiende que las razones de la existencia de este instituto jurídico son puramente técnicas.

En este sector, CUERNO LLATA considera que la extensión de efectos enfatiza el incremento de las garantías en la ejecución de las sentencias ${ }^{45}$. Asimismo, ROMERO REY va más allá y entiende que la razón última es únicamente de carácter procesal: crear un título de ejecución del mismo contenido que el que pretende una determinada sentencia firme, en favor de una persona que, aun no habiendo sido parte en el proceso donde ésta haya sido dictada, se encuentre en idéntica situación a las personas individualmente favorecidas por el fallo de dicha sentencia ${ }^{46}$.

Entre los máximos exponentes de esta corriente encontramos a ALUM LÓPEZ que considera que la extensión de efectos es únicamente «una medida de economía procesal que imprime celeridad y eficacia a la Justicia consistente en emplear una misma Sentencia para la resolución de litigios con idéntico objeto», clasificándola como mero remedio procesal ${ }^{47}$. De igual

${ }^{44}$ Vid. FONT I LLOVET, T., «la extensión a terceros de los efectos de la sentencia en vía de ejecución», ob. cit., pp. 166 y ss.

${ }^{45}$ Vid. CUERNO LLATA, J.R., «Extensión de efectos de las sentencias dictadas por los Tribunales de la Jurisdicción Contencioso-Administrativa», ob. cit., pp. 66 y ss.

${ }^{46}$ Cfr. ROMERO REY, C., en QUINTANA CARRETERO, J.P. (dir.), Comentarios a la Ley de la Jurisdicción Contencioso-Administrativa, ob. cit., p. 767.

47 Vid. ALUM LÓPEZ, C., «El proceso contencioso-administrativo en materia tributaria: extensión de efectos de sentencias y problemas de ejecución», en AA.VV., Nuevo régimen jurídico de los procedimientos tributarios, Estudios de derecho judicial, Consejo General del Poder Judicial, Madrid, 2005, núm.77, p. 474. La misma postura adopta MARTÍNEZ MICÓ, J.G., «Extensión de los efectos de una sentencia firme en materia 
manera, para MARTÍN FERNÁNDEZ el fundamento de la extensión de efectos no es más que salvaguardar el principio de economía procesal, al considerar absurdo llevar a cabo otro proceso cuando el Tribunal va a decidir en los mismos términos plasmados en una resolución firme anterior ${ }^{48}$. En la misma línea se manifiesta GRAU RUIZ ${ }^{49}$.

BAEZA DÍAZ-PORTALES, resume de forma muy acertada toda esta corriente al entender que el fundamento de la extensión es el articular un cauce procesal más sencillo para obtener una más pronta solución, evitando la multiplicidad de trámites y la más larga duración del proceso convencional ${ }^{50}$. Por último, PÉREZ DEL BLANCO entiende que la principal causa de la extensión de efectos de sentencias firmes es la economía procesal ${ }^{51}$.

\section{Visión jurisprudencial}

En un plano estrictamente jurídico, el Tribunal Supremo considera que son razones de carácter procesal las que fundamentan la existencia del art. 110 LJCA. Podemos verlo en el FJ $3^{\circ}$ de la STS 5476/2008, de 22 de octubre cuando expone:

«(...) Se trata, como es bien sabido, de un mecanismo dirigido a evitar procesos innecesarios cuando, sobre una situación idéntica a la que vaya a encarnar el tema de un litigio, existe ya un precedente judicial con carácter de firmeza; y pretende por ello dar cumplida satisfacción a los derechos a la igualdad en la aplicación de la ley y a la tutela judicial efectiva reconocidos en los artículos 14 y 24 de la Constitución.

tributaria», en Tribuna Fiscal, CISS, 2009, núm. 221, p. 11. En sentido similar: ARANGUREN PÉREZ, I., y GONZÁLEZ RIVAS J.J., Comentarios a la Ley reguladora de la Jurisdicción Contencioso Administrativa 29/1998 de 13 de Julio, Cizur Menor (Navarra), 2008, p. 1179.

${ }^{48}$ Cfr. MARTÍN FERNÁNDEZ, J., «Incidencia de la nueva Ley de la Jurisdicción Contencioso-administrativa en materia tributaria: suspensión de la ejecución del acto impugnado y extensión de los efectos de una sentencia firme a personas que no han sido parte en el procedimiento», en Revista de Información Fiscal, núm. 32, 1999, p. 34. Opinamos que esta afirmación es errónea, en tanto que el sistema del precedente no es una herramienta instalada en nuestro país, por lo que las sentencias pueden no seguir el mismo fundamento.

${ }^{49}$ Vid. GRAU RUIZ, M.A., «Cuestiones suscitadas en la extensión de los efectos de las sentencias en materia tributaria» en MONTOYA MELGAR, A. (coord.), Cuestiones actuales de la jurisdicción en España, Madrid, 2010, p. 1041.

${ }^{50}$ Cfr. BAEZA DÍAZ-PORTALES, M.J., «Extensión de los efectos de las sentencias a terceros (regulación legal, doctrina judicial y examen crítico)», en Tribuna Fiscal no 246 , Abril 2011, p. 9.

${ }^{51}$ Cfr. PÉREZ DEL BLANCO, G., «La extensión subjetiva de los efectos de las sentencia administrativa en los supuestos de litigios en masa», ob. cit., p. 88 . 
Ésa es la que pudiéramos llamar la vertiente sustantiva de la institución, pero también desde el punto de vista procesal tiene un perfil propio: su finalidad es crear un título de ejecución, del mismo contenido que el que presente una determinada sentencia firme, en favor de una persona que, aun no habiendo sido parte en el proceso donde esta haya sido dicta$d a$, se encuentre en idéntica situación a las personas individualmente favorecidas por el fallo de dicha sentencia. (...)».

En la misma línea se manifiesta el Tribunal Constitucional, en su STC 13/2011, de 28 de febrero de 2011, FJ $2^{\circ}$ :

«Tal objeción ha de ser rechazada de plano pues de la simple lectura del precepto indicado se desprende que la extensión de efectos de sentencias firmes que hubieran reconocido una situación jurídica individualizada en materia tributaria no se configura en la Ley reguladora de la jurisdicción contencioso-administrativa como un remedio procesal frente a Sentencias lesivas de la igualdad sino como un procedimiento preventivo y simplificador del procedimiento judicial, que no puede configurarse como una obligación del ciudadano, ni mucho menos entenderse su omisión como una renuncia al derecho a la igualdad en la aplicación judicial de la ley.»

Para un gran número de autores ${ }^{52}$ (encabezados por GIMENO SENDRA y a los que nos sumamos), además de la mejora de la eficacia en el seno judicial, el fundamento principal de la extensión de efectos del art. 110 LJCA se encuentra en la STC 10/1998, de 13 de enero y, especialmente, en el principio constitucional de igualdad en la aplicación de la Ley ${ }^{53}$, puesto que: «sería contrario al referido principio constitucional y al derecho a una tutela judicial efectiva y sin dilaciones indebidas que los litisconsortes nativos, que no reaccionaron, en su día, mediante el correspondiente recurso contenciosoadministrativo, se vieran ante la ejecutoriedad del acto, discriminados frente a los activos que decidieron interponer dicho recurso en tiempo y forma $»^{54}$.

De hecho, así lo ha corroborado el Tribunal Supremo, cuando en su STS 5886/2011, de 13 de septiembre ${ }^{55}$ en su FJ $6^{\circ}$ expone:

«(...) No cabe olvidar que la extensión de efectos se configura en la ley como un instrumento procesal dirigido a evitar la reiteración de procesos

${ }^{52}$ Vid. por ejemplo, PUEBLA AGRAMUNT, N., «QQuiere realmente el supremo acabar con la extensión de efectos en materia tributaria?», en Quincena Fiscal, 2009, núm. 18 , p. 17 .

53 De hecho, en su STS 2846/2018, de 18 de julio, FJ único, por el mismo principio de igualdad en la aplicación de la Ley no expone los razonamientos jurídicos al ser los mismos aplicados en una sentencia anterior que reproduce.

${ }^{54}$ Cfr. GIMENO SENDRA, V., MORENO CATENA, V. y SALA SÁNCHEZ, P., Derecho Procesal Administrativo, Madrid, 2004, p. 281.

${ }_{55}$ Rec. No $4418 / 2010$. 
contra los llamados actos masa y que se funda en el principio de igualdad en la aplicación de la ley por los tribunales, siendo presupuesto necesario la firmeza de la sentencia cuya corrección jurídica el Tribunal Supremo no puede ya revisar, salvo que se invoque que la doctrina determinante del fallo cuya extensión se postula fuese contraria a la jurisprudencia del Tribunal Supremo, circunstancia que no concurre en el caso.»

En la misma línea se expresa en su STS 3445/2018, de 9 de octubre, cuando en su FJ $2^{\circ}$ expresa:

«L expuesto nos lleva a recordar que las normas de los artículos 110 , 111 y 37.2 de la LJCA de 1998 sirven para garantizar el principio constitucional de igualdad en la aplicación jurisdiccional de la ley, además de evitar el coste y el retraso de la repetición de procesos en lo que se han denominado "actos en masa» en materia tributaria, de personal y de unidad de mercado. Y es evidente que, en este caso, el respeto a la igualdad nos vincula por partida doble, dado el número considerable de precedentes planteados como se ha dicho y que se han enumerado, lo que nos autoriza a examinar en forma breve esta impugnación. Las Administraciones deben acomodar su actuación, en la medida que les sea posible, a lo que resuelvan los Tribunales en casos en que los interesados se encuentran en idéntica situación fáctica y jurídica y acomodarse a lo resuelto o «juzgado», pero en este caso el recurso esgrime que no hay identidad de situaciones, lo que nos llevará a un examen más extenso de esa cuestión.»

Sin embargo, llama la atención el matiz sobre el que incide el Tribunal Constitucional, cuando entiende que la extensión de efectos no tiene como objetivo evitar la dispersión de resoluciones judiciales (STC 87/2008 de 21 de julio, $\mathrm{FJ}^{\circ}$ ):

«(...) el citado mecanismo procesal no tiene por objeto evitar la dispersión de soluciones judiciales, sin perjuicio de que pueda coadyuvar a ello, sino «ahorrar la reiteración de múltiples procesos innecesarios contra los llamados actos en masa», según el preámbulo de la Ley de la jurisdicción contencioso-administrativa. No cabe duda, por tanto, de que es constitucionalmente legitimo que los pronunciamientos sobre extensión del fallo se reserven al órgano que los dictó y que éste sólo pueda efectuar la extensión si tiene competencia para conocer de la nueva pretensión...»

No obstante, es el ATS 8103/2018, de 16 de julio el que, a nivel jurisprudencial, expone de forma más rotunda los fundamentos de la extensión de efectos de sentencias firmes para el ordenamiento jurídico nacional. De la siguiente forma se manifiesta en su FJ $3^{\circ}$ :

"(...)Las Administraciones deben acomodar su actuación, en la medida que les sea posible, a lo que resuelvan los Tribunales en casos en que los interesados se encuentran en idéntica situación fáctica y jurídica y acomodarse a lo resuelto o «juzgado» en supuestos como el que nos ocu- 
pa, lo que justifica las normas de los artículos 110, 111 y 37.2 LJCA, dictadas para garantizar el principio constitucional de igualdad en la aplicación de la ley y evitar el coste y el retraso de la repetición de procesos en lo que se han denominado actos en masa en materia tributaria, de personal y de unidad de mercado.»

Sin duda, es la previsibilidad de una resolución similar en un caso muy parecido el que llevar a poder exigir una extensión de efectos. En este sentido se ha manifestado el Tribunal Supremo en su STS 4529/2016, de 17 de octubre, FJ $5^{\circ}$ :

«(...) la LJCA considera que, ya que la extensión de los efectos de la sentencia no resulta exigible en virtud del estricto cumplimiento de la misma, sino más bien como consecuencia de la previsibilidad de una decisión idéntica en el proceso en que se plantee la misma cuestión, no puede darse lugar a dicha extensión cuando la existencia de jurisprudencia contraria impediría al juzgado o tribunal sentenciador reiterar la doctrina aplicada, sin perjuicio de que la sentencia deba mantener estrictamente sus efectos entre las partes como consecuencia del principio de cosa juzgada...»

\section{A MODO DE CONCLUSIÓN: OBJETIVOS DE LA FIGURA}

Como hemos podido comprobar, en muchos casos (y, sobre todo, desde los enfoques más técnicos) la fundamentación de base para entender el art. 110 LJCA se mezcla con su finalidad u objetivos. En este punto, nos mostramos totalmente de acuerdo con lo que declara MAGALDI cuando expone que los objetivos que se perseguían con la creación de la extensión de efectos eran: la descongestión judicial, la agilización de los trámites judiciales y de los plazos procesales, y la evitación de los pronunciamientos judiciales contradictorios $^{56}$. En la misma línea, se muestra CHAMORRO GONZÁLEZ, para el que la extensión de efectos es un mecanismo que surge con el objetivo de paliar "el endémico atasco en el que se encontraban los Órganos Judiciales» ${ }^{57}$.

${ }^{56}$ Cfr. MAGALDI, N., «La extensión de los efectos de las sentencias» en EZQUERRA HUERVA, A. (dir.) y OLIVÁN DEL CACHO, J.J., (dir.), Estudio de la Ley de la Jurisdicción Contencioso-Administrativa, Valencia, 2014, pp. 1024, 1053, 1054 y 1071. Asimismo, puede verse también ROJÍ BUQUERAS, J.M., «La extensión de los efectos de sentencias en materia tributaria (un análisis del art. 110 de la Ley 29/1998, de 13 de Julio reguladora de la Jurisdicción Contencioso-Administrativa)», en Impuestos: Revista de doctrina, legislación y jurisprudencia, 2001, Año núm. 17: núm.1, pp. 264 y 265.

${ }_{57}$ Cfr. CHAMORRO GONZÁLEZ, J.M., «La extensión de efectos de Sentencias del Orden Jurisdiccional Contencioso-Administrativo», en Tributos Locales, núm. 94, AbrilMayo 2010, p. 115. 
La pregunta que surge a continuación es la referente al grado de cumplimiento de estos objetivos iniciales. En nuestra opinión ${ }^{58}$, la extensión de efectos no ha gozado en el ordenamiento jurídico español (y especialmente en el ámbito contencioso-administrativo) del papel relevante que se pretendía con su incursión legal. El legislador ha ido poniendo trabas para su uso, modificando el articulado y delimitando cada vez unos requisitos muy estrictos, mientras que el ciudadano (y también muchos operadores jurídicos) en la mayoría de los casos ni siquiera conoce la existencia de la figura. Como expresan la mayoría de los autores, el balance sobre la utilización de este mecanismo es bastante desolador. Sin duda, su controvertida introducción en el ordenamiento y su difícil encaje procesal han provocado, en parte, esta situación, aunque en la materia de personal al servicio de las Administraciones Públicas parece que últimamente está volviendo a cobrar protagonismo.

Podría afirmarse que la fundamentación de la extensión de efectos únicamente responde a motivos de orden puramente práctico, motivos de carácter formal que, por la utilidad que ofrece la institución, van a provocar su aparición en el sistema contencioso-administrativo y que, por conformar los antecedentes, dieron lugar a la incorporación del art. 110 a la LJCA. No obstante, por otro lado, también existen razones sustantivas o materiales que fundamentan la extensión de efectos y que parecen supeditadas a las primeras. Sin embargo, bajo nuestro punto de vista son éstas las que poseen consistencia jurídica para incorporar una figura tan atípica y complicada como es la extensión de efectos de sentencias firmes. Igualmente, se evidencia que, aunque en su origen respondiese a otro tipo de pretensiones, actualmente esta institución puede encuadrarse en las nuevas tendencias que ha fomentado la Unión Europea para evitar o, al menos, reducir la litigiosidad ante los Tribunales de Justicia $^{59}$. Incluso, podría llegar a pensarse en la extensión de efectos más que

También es interesante traer aquí la opinión de MENÉNDEZ PÉREZ, S. (en BAENA DEL ALCÁZAR, M. [dir.], Ley Reguladora de la Jurisdicción Contencioso Administrativa, ob. cit., p. 702) cuando entiende que con la extensión de efectos de sentencias firmes se trata de «facilitar la solución de conflictos que son idénticos a otro u otros ya decididos por sentencia firme, enfrentando a la Administración con esta decisión a la hora de tomar postura, aligerando la carga de trabajo, tanto de tramitación como de decisión que pesa sobre los órganos judiciales y, en fin, dificultando la adopción de soluciones contradictorias en casos idénticos».

${ }_{58}$ En la misma postura se encuentra la mayoría de la doctrina. Vid. por ejemplo IBÍDEM o CÓRDOBA CASTROVERDE, D., «Réquiem por la extensión de efectos de las sentencias en el orden contencioso-administrativo», en Revista de Jurisprudencia el Derecho, Febrero, 2007, núm. 2, pp. 1 y ss.

${ }_{59}$ Como ejemplo de estas tendencias podemos citar el fomento por parte de la UE del uso de los sistemas alternativos de resolución de litigios y, especialmente la creación de la plataforma de resolución de litigios en línea. 
como derecho sustantivo en una especie de norma soft law, ya que, con el art. 110 LJCA nos encontramos ante un artículo de opción potestativa para el ciudadano pero que, con su uso, puede llegar a influir en la calidad judicial.

\section{BIBLIOGRAFÍA}

Agúndez Fernández, A. (dir.), et al., El proceso Contencioso Administrativo, Comentarios y Jurisprudencia a la Ley 29/1998 de 13 de Julio (Actualizada a la Ley 37/2011 de 10 de Octubre), Comares, Granada, 2013.

ALUM LÓPEZ, C., «El proceso contencioso-administrativo en materia tributaria: extensión de efectos de sentencias y problemas de ejecución», en A.A.V.V., Nuevo régimen jurídico de los procedimientos tributarios, Estudios de derecho judicial, Consejo General del Poder Judicial, Madrid, 2005, núm.77.

Aranguren Pérez, I., y GonzÁlez Rivas, J.J., Comentarios a la Ley reguladora de la Jurisdicción Contencioso Administrativa 29/1998 de 13 de Julio, Cizur Menor (Navarra), 2008.

Baena del Alcázar, M. (dir.), Ley Reguladora de la Jurisdicción Contencioso Administrativa. Doctrina y Jurisprudencia, Trivium, Madrid, 1999.

Baeza Díaz-Portales, M.J., «Extensión de los efectos de las sentencias a terceros (regulación legal, doctrina judicial y examen crítico)», en Tribuna Fiscal n 246 , Abril 2011.

Calvo Díaz, G., «Extensión de efectos de las sentencias dictadas por los Tribunales de la Jurisdicción Contencioso-Administrativa. Comentario al artículo 86.2 de la Ley de la Jurisdicción Contencioso-Administrativa», en Actualidad Administrativa, núm.30, 1991.

Chamorro GonzÁlez, J. M., «La extensión de efectos de Sentencias del Orden Jurisdiccional Contencioso-Administrativo», en Tributos Locales, núm. 94, AbrilMayo 2010.

Civera Martínez, M. y Abad Carretero, L., En pos de un nuevo Humanismo, Santander, 2018.

Contín Trillo-Figueroa, E., «Extensión de los efectos de la sentencia en la Jurisdicción Contencioso-Administrativa», en Revista Aragonesa de Administración Pública, núm. 32, Junio, 2008.

Cordero Lozano, F., «La extensión de los efectos de la sentencia a terceros; un nuevo reto jurisdiccional» en Administración de Andalucía: revista andaluza de Administración Pública, núm. 47, 2002.

CóRDOBa CASTROVERde, D., «Dificultades y problemas que plantea en la actualidad la extensión de efectos de las sentencias en el orden contencioso-administrativo», en Revista de Jurisprudencia El Derecho núm. 4, Diciembre, 2011.

—_, «Réquiem por la extensión de efectos de las sentencias en el orden contencioso-administrativo», en Revista de Jurisprudencia el Derecho, Febrero, 2007.

Cubillo LóPez, I.J., «El derecho a la tutela judicial efectiva y el derecho a la ejecución en la jurisprudencia constitucional». Estudios de Deusto 66, 2018.

Cuerno Llata, J.R, «Extensión de efectos de las sentencias dictadas por los Tribunales de la Jurisdicción Contencioso-Administrativa», en Revista de Estudios 
Locales CUNAL, El Consultor de los Ayuntamientos y de los Juzgados, 1998, núm. 22.

De Diego DíEz, L.A., Extensión de efectos y pleito testigo en la Jurisdicción Administrativa, Cizur Menor (Navarra), 2016.

De la Oliva Santos, A., Sobre la cosa juzgada: civil, contencioso-administrativa y penal, con examen de la jurisprudencia del Tribunal Constitucional, Madrid, 1991.

DíEz PICAZO, L.M., «La doctrina del precedente administrativo», en Revista de Administración Pública, núm. 98, 1982.

Ezquerra Huerva, A., y Oliván Del CACHo, J., Estudio de la Ley de la Jurisdicción Contencioso-Administrativa, Tirant Lo Blanch Tratados, Valencia, 2014.

FONT I LlOVET, T., «la extensión a terceros de los efectos de la sentencia en vía de ejecución», en Justicia Administrativa: Revista de Derecho Administrativo, núm. extraordinario de 1999.

Gimeno Sendra, V., Moreno Catena, V. y Sala Sánchez, P., Derecho Procesal Administrativo, Centro de Estudios Ramón Areces, Madrid, 2004.

Gómez-Ferrer Morant, R., «Artículo 111», en Revista Española de Derecho Administrativo núm. 100, 1998.

Huerta Garicano, I. y DE la Cruz Mera, F., «La extensión de efectos como cauce alternativo a la interposición del recurso contencioso-administrativo» Foro Abierto, Revista de Jurisprudencia El Derecho, núm. 2, 2011.

López Benitez, M., «Comentarios a la Ley de la Jurisdicción Contencioso-Administrativa de 1998», en Edición especial del núm. 100, Revista Española de Derecho Administrativo, 1999.

MARTín FERnÁndEZ, J., «Incidencia de la nueva Ley de la Jurisdicción Contenciosoadministrativa en materia tributaria: suspensión de la ejecución del acto impugnado y extensión de los efectos de una sentencia firme a personas que no han sido parte en el procedimiento», en Revista de Información Fiscal, núm. 32, 1999.

Martínez Micó, Juan Gonzalo, «Extensión de los efectos de una sentencia firme en materia tributaria», en Tribuna Fiscal, CISS, núm. 221, 2009.

MERINO JARA, I. (dir.) et al., Estudios sobre el proceso contencioso-administrativo en materia tributaria, Bosch, Barcelona, 2015.

Montoya Melgar, A. (coord.), Cuestiones actuales de la jurisdicción en España, Real Academia de Jurisprudencia y Legislación, Madrid, 2010.

Moreno Molina, J.A., (dir.) et al., Procedimiento y Proceso Administrativo Práctico (Vol. III, Proceso Contencioso-Administrativo), La Ley, Madrid, 2006.

Ortega y Gasset, J., La rebelión de las masas (edición de Hernández Sánchez, D.), Tecnos, Madrid, 2012.

Palomar Olmeda, A. (dir.) et al., Tratado de la Jurisdicción Contencioso- Administrativa, Aranzadi Thomson Reuters, Cizur Menor (Navarra), 2012.

Pendás GarcíA, B. (coord.), Ley de la Jurisdicción Contencioso-Administrativa. Estudio sistemático, Praxis, Barcelona, 1999.

Pera Verdaguer, F., Comentarios a la Ley de lo Contencioso Administrativo, Bosch, Barcelona, 2004.

PÉrez Andrés, A.A., Los Efectos de las Sentencias de la Jurisdicción ContenciosoAdministrativa, Aranzadi, Elcano (Navarra), 2000. 
PÉREZ DEl Blanco, G., «La extensión subjetiva de los efectos de las sentencia administrativa en los supuestos de litigios en masa» en CEFLegal, Junio, núm. 53, 2005.

Puebla Agramunt, N., «¿Quiere realmente el supremo acabar con la extensión de efectos en materia tributaria?», en Quincena Fiscal, núm. 18, 2009.

Quintana Carretero, J.P., (dir.), Comentarios a la Ley de la Jurisdicción Contencioso-Administrativa, Thomson-Reuters, Valladolid, 2013.

Quintana Redondo, C. et al., Comentarios a la Ley de lo Contencioso-Administrativo, Santillana, Madrid, 1965, vol. II.

RoJí BUQUERAS, J.M., «La extensión de los efectos de sentencias en materia tributaria. (Un análisis del art.110 de la Ley 29/1998, de 13 de Julio, reguladora de la Jurisdicción Contencioso-Administrativa)», en Impuestos: Revista de doctrina, legislación y jurisprudencia, Año núm. 17: núm.1, 2001.

Rosende Villar, C., La Eficacia Frente a Terceros de las Sentencias ContenciosoAdministrativas, Aranzadi, Cizur Menor (Navarra), 2002.

SANTAMARÍA PAStOR, J.A., La Ley reguladora de la Jurisdicción Contencioso- Administrativa. Comentario, Iustel, Madrid, 2010.

SenÉs Motilla, C., «La ejecución de las sentencias en la nueva Ley de la Jurisdicción contencioso-administrativa», en La Ley: Revista jurídica española de doctrina, jurisprudencia y bibliografía, núm.6, (D-323), 1998.

Vega CASTRO, J.L., «La extensión a terceros de los efectos de las sentencias dictadas por los Tribunales de la Jurisdicción Contencioso-Administrativa en el seno de la vía de ejecución: una solución problemática», en AAVV., La Justicia Administrativa, Libro Homenaje al Prof. Dr. D. Rafael Entrena Cuesta, Atelier, Barcelona, 2003.

Xiol Ríos, J.A., «Consideración de algunos aspectos del proceso administrativo como respuesta a los fenómenos de masificación social: la legitimación, la limitación de las instancias, el tratamiento en serie de los recursos y los efectos de la sentencia», en «Jurisdicción contencioso-administrativa: aspectos procesales», Cuadernos de Derecho judicial, Madrid, Consejo General del Poder Judicial, 1992, XV. 


\title{
HISTORIA Y FUNDAMENTOS DE LA EXTENSIÓN DE EFECTOS DE SENTENCIAS FIRMES COMO FIGURA PROCESAL AUTÓNOMA
}

\author{
History and foundations of the extension of effects of final \\ judicial sentences as autonomous procedural figure
}

\author{
María Luisa Domínguez Barragán \\ Profesora de Derecho Procesal \\ Universidad de Córdoba \\ mldominguez@uco.es
}

http://dx.doi.org/10.18543/ed-67(2)-2019pp235-261

\section{Copyright}

Estudios de Deusto es una revista de acceso abierto, lo que significa que es de libre acceso en su in tegridad. Se permite su lectura, la búsqueda, descarga, distribución y reutilización legal en cualquier tipo de soporte sólo para fines no comerciales, sin la previa autorización del editor o el autor, siempre que la obra original sea debidamente citada y cualquier cambio en el original esté claramente indicado

Estudios de Deusto is an Open Access journal which means that it is free for full access, reading, search, download, distribution, and lawful reuse in any medium only for non-commercial purposes, without prior permission from the Publisher or the author; provided the original work is properly cited and any changes to the original are clearly indicated. 